\title{
Considerations Upon Pterygium Perception in Terms of Symptoms Induced by Inflammatory Response, According to Sex and Age
}

\author{
MARIA FILOFTEA (NICOLCESCU) MERCUT, STEFANIA CRAITOIU, ALIN STEFANESCU DIMA*, CARMEN LUMINITA MOCANU, \\ ANDREEA TANASIE, IRINA MERCUT, MIHAELA IONESCU \\ University of Medicine and Pharmacy of Craiova, 2-4 Petru Rares Str., 200349, Craiova, Romania
}

\begin{abstract}
Pterygium is a common eye disease, which affects both males and females, and is usually described by most patients as painless and unaesthetic. In case pterygium is symptomatic, the perceived ocular discomfort level is determined by a series of symptoms, among which we have studied tearing, foreign body sensation and blurred vision. Based on patients' evaluation, we have generated a perception score regrouping the presence or absence of symptoms, and we have analysed it according to various age decades and sex. In this study, our data revealed a correlation between the presence of the studied symptoms and the size of the lesion measured when patients opted for professional medical care $(P<0.01)$. We have also determined that males and females with similar lesions in terms of size have a different perception upon pterygium; there are also differences regarding symptoms presence or absence, for various age decades and lifestyle context. In general, pterygium perception score indicated that males are more constant in their evaluation, presenting increased score values for higher ages; females tend to seek out medical treatment later than males, especially for higher ages, and present greater perception scores which do not seem to be correlated with age decades.
\end{abstract}

Keywords: pterygium, chemical mediators, cytokines, T-lymphocytes

Pterygium is an inflammatory ocular disease, characterized by an abnormal conjunctival or fibrovascular thick vascularized growth, with a triangular shape and generally a nasal location. Pterygium has three components: the head that corresponds to the tip of the lesion, has a grey colour and it is not vascularized; the neck connects it to the body and presents neoformation and anastomotic blood vessels; the body represents the largest area, with multiple blood vessels that assure the lesion nutrition and presents a straight or a radial aspect, from the tip towards the body of the lesion. Pterygium may be composed by small atrophic lesions, or by large aggressive lesions, with a rapid fibrovascular progression, inflammatory infiltration (through the presence of Tlymphocytes), degraded extracellular matrix, that may alter the cornea structure and, in severe cases, lesions may even surround the optical centre of the cornea, inducing astigmatism [1-2].

Pterygium etiopathogeny is not completely known. Current literature considers the following risk factors: prolonged UV exposure [3-6], smoking [3], residency area (urban or rural) directly correlated with UV exposure and work conditions [7-8]. Higher age and sex are also considered as risk factors [9-10], and even repeated microtraumatisms, through dust exposure, chronic conjunctival inflammation, genetic predisposition and dry eye syndrome, which would indicate a multifactorial pathogenesis [11]. Lately, researchers have extensively studied pterygium pathogenesis and made an important progress, showing that this is a complex disease with genetic components, influenced by environmental, infectious and immunological factors [12]. Sun N associates pterygium with pyroptosis - a programmed cell death, recently discovered, and known as being related to oxidative stress [13].

From a clinical point of view, pterygium generates a series of symptoms like irritation, foreign body sensation (FBS), tearing, physiognomy changes and functional reactions like a visual field reduction, astigmatism, diplopia and difficulties in wearing contact lenses.

Pterygium treatment may be medical for symptomatic or asymptomatic patients, consisting in ocular lubricants instillations, or short cycles of topic corticosteroids, as well as encouraging patients to wear sunglasses in order to reduce the UV exposure.

The elected treatment is the surgical removal of lesions, through multiple techniques: lesion excision with simple conjunctival suture (bare sclera), conjunctival autograft reconstruction, usage of tissue adhesives, adjuvant therapy with antimetabolites (5-fluorouracil and C-Mythomicine), usage of amniotic membranes for conjunctiva reconstruction [14].

Various studies reported a high recurrence in case of bare sclera technique, and better results in case of conjunctival autograft reconstruction, associated with intraoperative adjuvant therapy with C-Mythomicine [1416].

The purpose of this study is to define and evaluate the level of pterygium perception according to age and sex, considering the patients admitted in the Ophthalmology Clinic of the Emergency County Hospital Craiova, emphasizing the context of their disease, treatment and potential recurrence.

\section{Experimental part}

\section{Material and Method}

Our study took place in the Ophthalmology Clinic of the Emergency County Hospital Craiova, between 1st of March 2017 and 1st of March 2019, where 4269 patients were admitted for various ocular diseases. Our inclusion criteria was a diagnostic of pterygium and corresponding surgical treatment, thus 118 patients were eligible for our study. All patients gave their informed consent upon participating to this study, which was approved by the Ethic Committee from the University of Medicine and Pharmacy of Craiova.

*email:stefanescu.alin@gmail.com, Phone: +40745597250

REV.CHIM.(Bucharest) $70 \diamond$ No.9 $2019 \quad$ http://www.revistadechimie.ro 
All patients were subject to a complete and thorough eye examination before surgery, including visual acuity and slit-lamp investigation.

For easy computations and associations between symptoms and lesions, we have quantified most of these parameters as quantitative variables. Lesions have been categorized according to their size (in $\mathrm{mm}$ ) measured before the surgical treatment. Only these values are taken into account. We did not perform a study of lesions' progress in time. Patients included in our study lotpresented lesions with sizes between $1 \mathrm{~mm}$ and $8 \mathrm{~mm}$.

We have subsequently performed a division of our study lot, according to patients' age, obtaining 6 decades: 35-45 years old was the first decade, followed by 46-55 years old, the final one being $86-95$ years old. Furthermore, this classification allowed us to determine whether there are changes in pterygium perception, determined by age progression.

Symptoms were evaluated based on their presence / absence using a dual YES/NO variable (with the numeric equivalent 1/0). According to these values, we have created a perception score based on summing the numerical equivalents of the analysed symptoms. A patient may have a 0 score if his/her evaluation indicates all symptoms as absent. Similarly, a patient may present the maximum score if his/her symptom evaluation indicates all of them as present.

We performed our statistical analysis using Microsoft Office Excel (San Francisco, USA). We used Chi-square and T-student tests to determine groups' distributions and their compared differences. The significance level was set to $5 \%(p<0.05)$.

\section{Results and discussions}

Our study lot included 118 patients, composed by 58 females and 60 males, with ages varying between 35 and 91 years old (mean value $65.38 \pm 11.6$ ). The group had a normal distribution, with a peak in decade 4 (around a third of the patients were included in this decade: 40 patients, 33.9\%). Patients from this decade are equally distributed according to sex ( 20 males, 20 females). From this point of view, decades are relatively homogenous, except decade 2 where males have a significant majority (13 out of 15 patients). Pterygium lesions mean size, measured right before surgery, is quite similar for both males and females, slightly larger differences being observed for decades 3 and 6 . However, except the first decade, lesion mean size for females was at least equal or larger than for males (Figure 1).

For all patients included in our study, we have analysed their medical history: cataract, arterial hypertension,

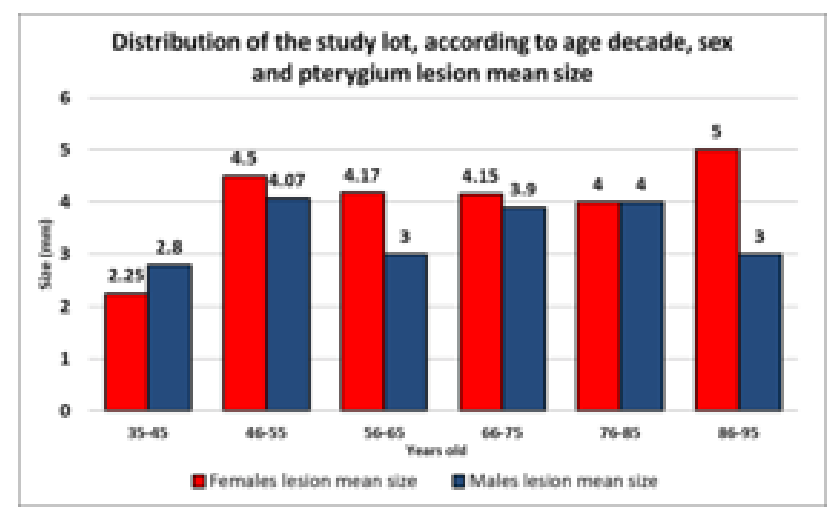

Fig. 1. Distribution of the study lot according to age decade, sex and lesion mean size diabetes mellitus, cardiomyopathy, asthma, pulmonary thromboembolism, primary open angle glaucoma, primary closed angle glaucoma, Sicca Syndrome. We found no correlation between these antecedents and the size of the lesions (measured rightbefore surgery), bilaterality, double pterygium or recurrence $(p>0.05)$.

From the symptomatology associated with pterygium, we have included in the present study tearing, FBS and blurred vision.

Tearing was a common symptom, affecting 94 patients ( $79.66 \%$ of the total study group), 49 females and 45 males, most of them included in age decades 4 and 5 . More than 2 thirds of the patients from decades 2 to 6 presented this symptom, in comparison with the very young patients from the first decade who did not indicate tearing as present. The mean size of pterygium lesions for patients with tearing was $4.14 \mathrm{~mm}$, in contrast with the group without tearing, who exhibited a mean size of $2.58 \mathrm{~mm}$. This indicates a potential correlation between those two factors, as patients with larger lesions tend to present tearing ( $p<0.01)$. An analysis on age decades indicates that at least $40 \%$ of patients from each decade are affected by tearing (both males and females). Also, for males, there is a slight tendency of the percentage of impacted patients to increase with age (Figure 2a). All females with ages between 46 and 55 years (decade 2) presenttearing (Figure 2b). Pterygium lesions mean size is relatively similar for all decades (bigger differences may be observed for decades 1,3 and 6 ).

Foreign body sensation was less common, being present for only 50 patients ( $42.37 \%$ of the total study group). The distribution according to sex was almost equal, with 26 females and 24 males. Less than half of patients from each decade were affected, excepting decades 2 and 6 for males, respectively decade 4 for females (Figure $2 \mathrm{c}$ ). A comparison of the mean size of pterygium lesions indicates that patients with larger lesions seem to exhibit FBS more frequent than those with smaller lesions $(4.58 \mathrm{~mm}$ mean size for patients with this sensation, and $3.28 \mathrm{~mm}$ for the others) $(p<0.01)$. Lesions mean size is decreasing with age for females, starting with decade 2; whilst for males is rather oscillating (Figure $2 \mathrm{~d}$ ).

Blurred vision affected $54.24 \%$ of our study lot ( 64 patients, 32 females, 32 males). Regarding the distribution on age decades, more than half of the patients from decades 4,5 and 6 presented this symptom, in comparison with the younger patients from our study lot (aged up to 65 years old) who did not report obscured vision (decreased visual acuity could be related to age related changes in the lens (cataract) in this age group). The percentage of females with impacted vision is increasing with age; same for males, except for decade 3 ( 56 to 65 years old) (Figure $2 \mathrm{e}, 2 \mathrm{f})$. Pterygium lesion mean size is greater for females with vision problems from all decades, a minor negative difference being observed for decade 5. Like for the previous two symptoms, the mean size of pterygium lesions is greater for patients with blurred vision $(4.48 \mathrm{~mm})$, compared to a mean size of $3.05 \mathrm{~mm}$ for patients with normal vision $(p<0.01)$

The distribution of the study group according to pterygium perception scores indicates that females are more affected by the associated symptomatology, but in the same time, they present a larger fluctuation of scores with age. We cannot identify a tendency of perception, either increasing, or decreasing, according to age. For males, score 0 decreases constantly as the age increases. Score 1 has a normal distribution, with a peak in decade 3. Score 1 has a relative constant increasing evolution, while 

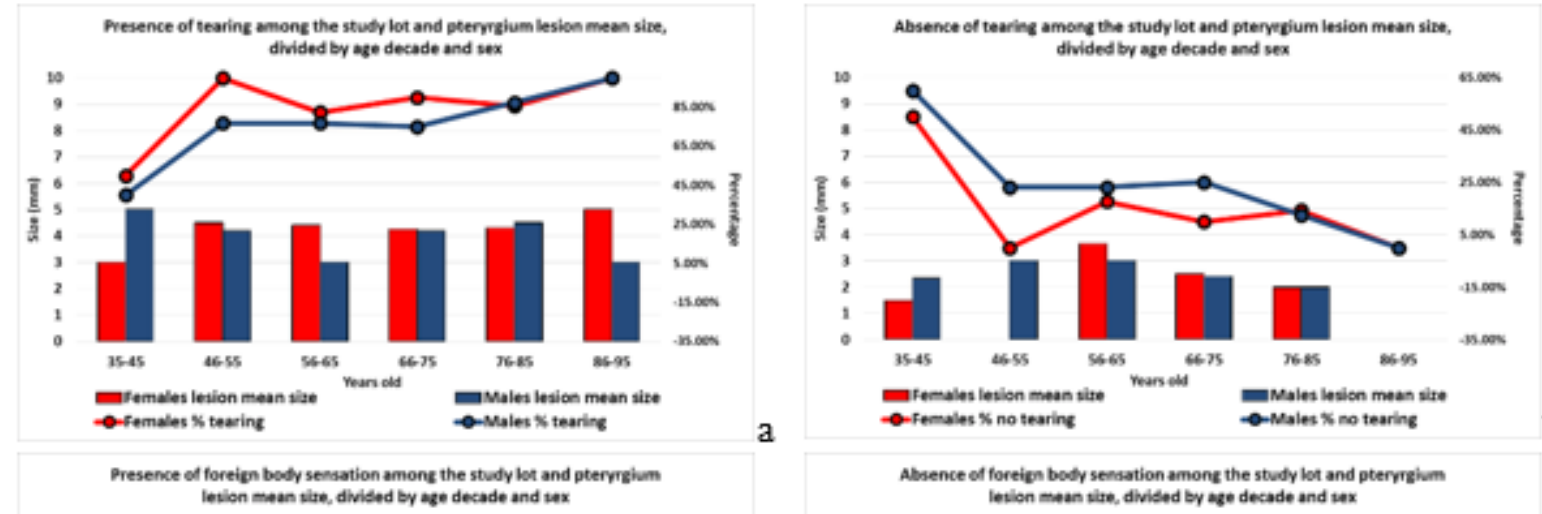

b
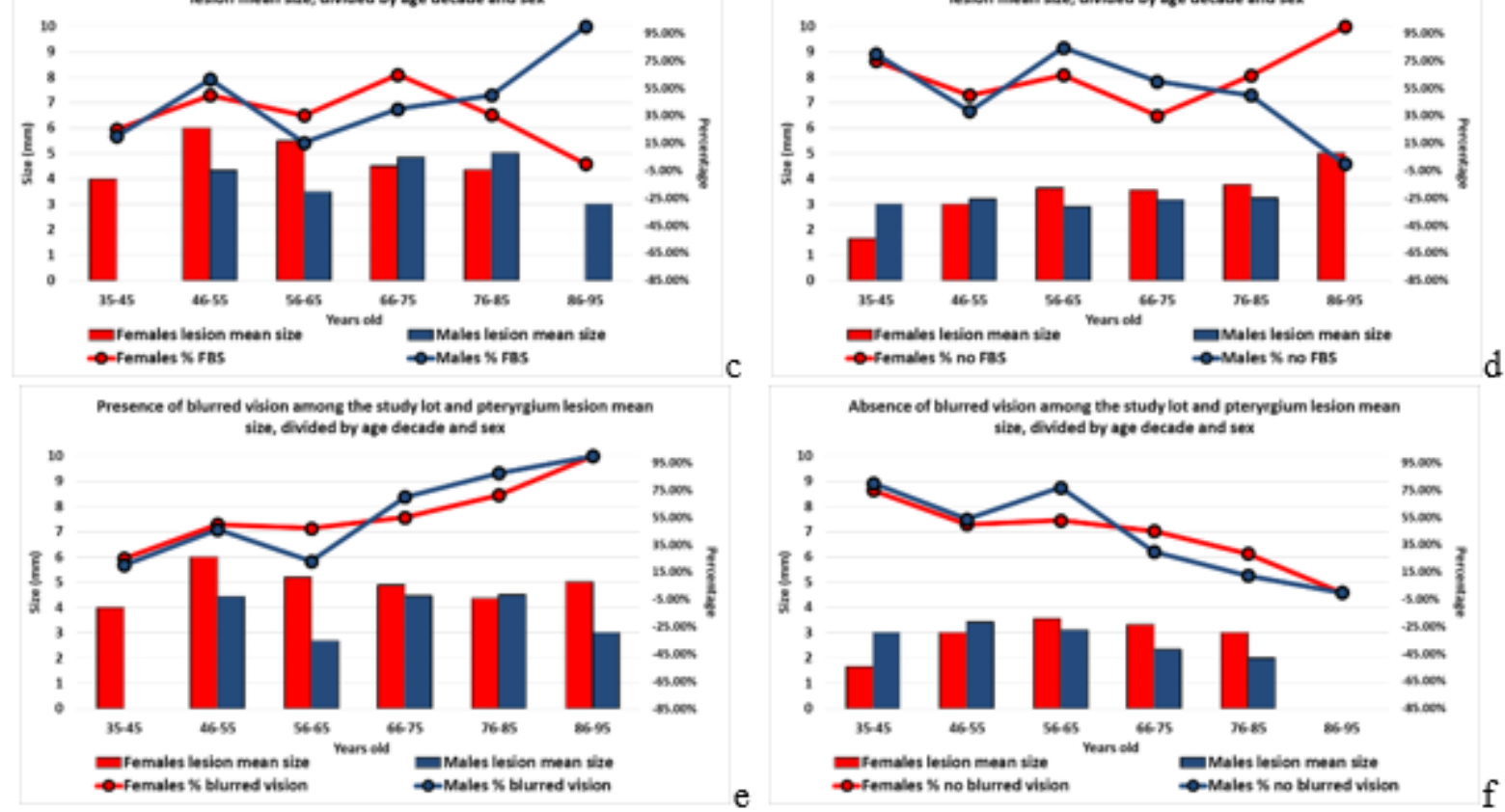

Fig. 2. Presence/absence of symptoms (a/b. tearing, c/d. foreign body sensation, e/f. blurred vision) expressed as percentage of impacted patients, and the mean size of pterygium lesions, divided by age decade and sex

score 3 has a bimodal distribution, with peaks in decades 2 and 6. Perception scores are displayed in Figure 3.

Pterygium lesions may be present unilateral, or on both eyes. In our study lot, 78 patients representing $66.1 \%$ of the total study lot ( 40 females, 38 males) presented unilateral 0 , while 40 patients representing $33.9 \%$, (18 females, 22 males) had both eyes affected, even if they opted for surgery on a single eye, probably the most affected. For lesions between 1 and $4 \mathrm{~mm}$, the number of patients with unilateral pterygium is significantly larger than those with bilateral pterygium. In contrast, for lesions between 5 and
$8 \mathrm{~mm}$, there are more patients with bilateral lesions (Figure 4).

From our study lot, 8 patients (6.7\%) had double pterygia, with lesions present both nasal and temporal, and sizes varying from 2 to $8 \mathrm{~mm}$; also $87.5 \%$ of them are included in age decades 2 to 4 . Six of them presented also bilateral affectation.

All patients from our study lot underwent surgery for one affected eye. For 98 patients ( 49 males and 49 females), representing $83.05 \%$, the surgeon opted for lesion excision with simple conjunctival suture (bare sclera).

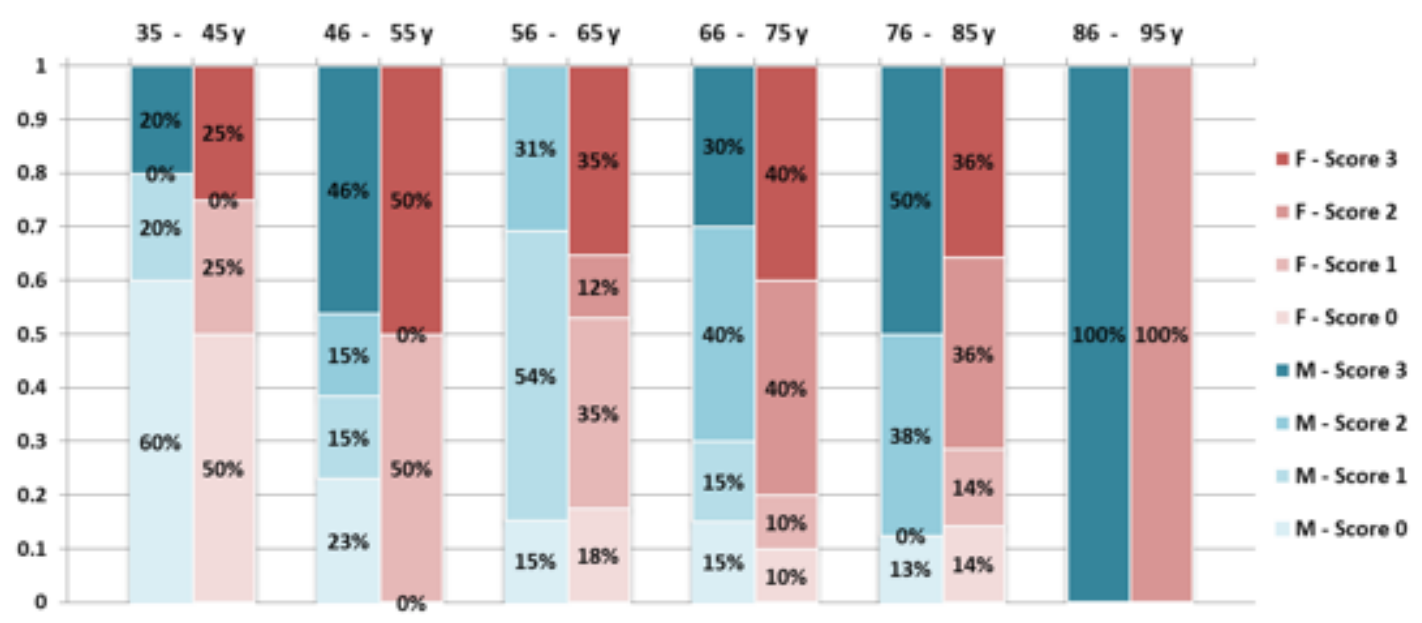

Fig. 3. Distribution of perception scores, according to sex ( $M$ - males, F - females) and age decade 


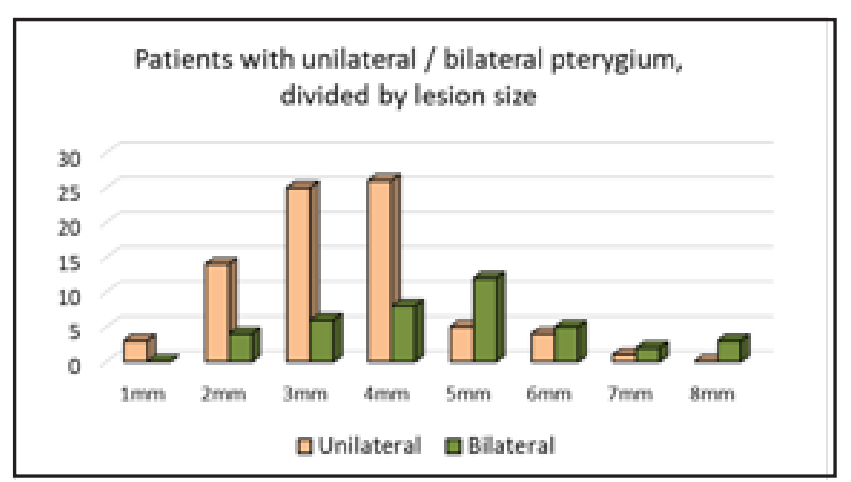

Fig. 4. The number of patients with unilateral and bilateral pterygium, divided by lesion size

These patients have ages included in all decades, and lesions of all sizes. For 19 patients ( 12 males and 7 females), representing $16.1 \%$ of the total study group, the treatment included a conjunctival autograft. Pterygium mean size for females was 5, while for males it was 3.66 (no male had lesions larger than $6 \mathrm{~mm}$, while females had lesions of 7 and even $8 \mathrm{~mm}$ ).

A major issue after pterygium surgery is recurrence. From our study lot, 12 patients ( 7 males and 5 females) had underwent pterygium removal in the past, thus seeking now recurrence treatment; they had ages between 44 and 75 years old, and lesions varying from $2 \mathrm{~mm}$ to 6 $\mathrm{mm}$. Eight patients (66.67\%) had lesions above $4 \mathrm{~mm}$ (4 males, 4 females). Nine patients (75\%) presented bilateral pterygia ( 4 males, 5 females).

Pterygium may be categorized as asymptomatic, when its size is small enough and does not produce discomfort to the patient, and symptomatic when either the size of the lesion or the associated symptoms determine the patient to seek professional treatment [17]. Pterygium is considered painless by most patients. Given the nature of pterygium lesions, even when it is symptomatic, it usually generates at most irritation, itching or burning sensation, tearing, red eye or foreign body sensation, determining a mild eye pain [18-19]. Zidi et al. have demonstrated that the clinical redness is significantly correlated with the chronic inflammatory response $(P<0.001)$ [1]. Signs of blurred vision appear when the lesion is significantly grown and it partially covers the cornea [20], obscuring the visual axis, or it may determine astigmatism [15].

Pterygium is perceived at a certain level by all patients, based on their discomfort tolerance, presence of symptoms or lesion size. Patients may be physically affected by it or may only perceive it as unaesthetic.

For our study lot, after the compared analysis of lesion mean sizes, we observed that females from the first decade (younger than 45 years old) sought medical treatment for lesions smaller than those of males with similar ages. Since the general lesion mean size for this age group is $2.5 \mathrm{~mm}$, the most probable reason for females to opt for surgery is an aesthetic one. Males from this age group probably came due to discomfort reasons.

Regarding age decades 2 to 6 , females presented lesion mean sizes larger than males. Values from decade 5 are equal for both sexes, but all other indicate that they tend to present to the doctor for larger lesions then males from the same age decade. To our knowledge, there are no similar studies, based on lesion sizes measured before surgery and associated symptoms, in order to correlate our findings. Zidi et al. have searched for a connection between the extent of pterygium lesions and the chronic inflammatory response, identifying a reverse correlation between those two parameters, but did not perform a comparison between males and females [1]. In fact, UV light, which is one of the main factors in pterygium formation [21], induces a series of chronic inflammation cells within the conjunctiva. Thus pterygium may be considered an inflammatory process, as the level of IL-6 and IL-17A (interleukines which are pro-inflammatory cytokines) is significantly higher in patients with pterygium, compared to healthy subjects.

There are numerous studies which emphasize the difference of inflammatory response in males and females for various diseases and conditions [22-24], which would explain these results. In fact, it was demonstrated that females tend to have a higher number of leukocytes (more macrophages and more T and B lymphocytes) compared to males, more than double, this difference being explained by various values of tissue chemokines; also, resident leukocytes have a different phenotype in males and females [25]. Thus, the inflammatory response may, at least partially, justify the difference of pterygium lesion sizes for males and females.

Among the studied symptoms, tearing was the most common one. This fact may be explained by the important presence of inflammatory chemical mediators (IL- 6 and IL-17A) in patients' tears. For decade 2 (46-55 years), all females presented this symptom, which could also be related to the alteration in the balance of sex hormones due to perimenopausal and menopausal changes, factors incriminated in dry eye disease pathophysiology [26]. Overall, tearing affected more than $75 \%$ of our study group. This result is not unusual, since it is scientifically demonstrated that abnormalities of the tear film represent an impacting factor in pterygium aetiology [27], but also pterygium surgery and autograft transplantation leads to a temporary restoration of the tear film functions [28], if it was previously impaired. Following this hypothesis, Kampitak etal. used artificial tears (based on hydroxypropyl methylcellulose) as an adjunctive drug after surgery, obtaining a reduction of around $50 \%$ in pterygium recurrence [29]. Also, according to Onkar et al, it is important to maintain if possible, the tear functions, as it tends to curb the wings of the expanding pterygium [27]. The interrelation between tears and pterygium is in fact quite complex.

The percentage of patients with blurred vision increased almost constantly with age, with a single exception: males from decade 3 ( $56-65$ years old) where less than a quarter were affected, and they also had a lesion mean size of $2.66 \mathrm{~mm}$, which is smaller than the average size for the entire decade $(3.66 \mathrm{~mm})$, both males and females being taken into account. More than half of patients older than 65 years old indicated the presence of blurred vision. However, at this age, patients may also presentother ocular pathology that was not included in this study, so pterygium may not be the only cause for this symptom.

Foreign body sensation was the third symptom that we have analysed more in detail, being present for less than half of our study group. Given the nature of this lesion, one would expect that patients with larger lesions would most likely indicate this symptom as present (and potentially disturbing). However, several patients with large lesions $(6-7 \mathrm{~mm})$ declared they were not bothered by their condition. All of them were female, aged above 58, two from the countryside, one from the urban area. Also, all three females had primary pterygium, so we can exclude that fact that the perception was already known from previous occurrences.

According to our study, females seem to be more susceptible to these symptoms, similar results being 
Table 1

PERCENTAGE DIFFERENCES BETWEEN PTERYGIUM LESION MEAN SIZE AND NUMBER OF AFFECTED PATIENTS FOR TEARING, FBS, BLURRED VISION

\begin{tabular}{|l|c|c|}
\cline { 2 - 3 } & \multicolumn{2}{|c|}{ Percentage difference } \\
\hline Tearing & $\begin{array}{c}\text { Number of } \\
\text { affected patients }\end{array}$ & $\begin{array}{c}\text { Pterygium lesion } \\
\text { mean size }\end{array}$ \\
\hline Foreign body sensation & $13 \%$ & $21 \%$ \\
\hline Blurred vision & $11 \%$ & $14 \%$ \\
\hline
\end{tabular}

obtained by Wanzeler etal. [20]. For tearing, FBS and blurred vision, the number of females presenting them was slightly greater than the number of males and, in general, females with these symptoms had lesions with bigger sizes. However, the difference in size does not justify by itself the difference in perceiving the symptom.

We have analysed both for females and males, the percentage difference in size and in number of patients affected by a specific symptom (since the perception of that symptom is defined as a yes/no answer). The results are indicated in Table 1 and may be justified by the fact that females tend to have a greater sensibility to pain [30], but also a higher tolerance to pain or discomfort [31].

The presence or absence of symptoms was assessed before surgery, so pain memory may have influenced also the final perception upon patients' lesions, as Loren et al. have demonstrated that males and females remember pain differently [32].

One more factor that may influence the perception upon the pterygium lesions is stress, which affects the pain sensibility and threshold. Wolkoff P. demonstrated that occupational stress decreases the pain threshold for eye irritation [33], which is a key element in perceiving pterygium. Since it is known that females are more affected by stress than males [34], it is more difficult to quantize their perception upon pterygium, and this may justify the oscillating results in score evaluation for females.

\section{Conclusions}

Pterygium perception is clearly different between women and men of different ages. If males are more constant in their symptom evaluations (indicating a potential association with age), females are more influenced by external factors (pain sensitivity and threshold, stress, pain memory) and presented more variable evaluations.

Pterygium size correlates with the presence of all three evaluated symptoms (tearing, foreign body sensation, blurred vision), most likely amplifying its perception for both males and females. Even though females are more susceptible to pterygium perception, they tend to delay the surgical treatment, presenting to the doctor when their lesions are considerably large.

We limited our current study to four factors, but we'll extend the context of pterygium perception in the following studies, to include triggering factors and lesion progression.

\section{References}

1. ZIDI, S., BEDIAR-BOULANEB, F., BELGUENDOUZ, H., BELKHELFA, M., MEDJ EBER, O., LAOUAR, O., HENCHIRI, C., TOUIL-BOUKOFFA, C., Int J Immunopathol Pharmacol, 30, 2017, p. 395.

2. ANGURIA, P., CARMICHAEL, T., NTULI, S., KITINYA, J., Afr Health Sci, 13, 2013, p. 725.
3. ASOKAN, R., VENKATASUBBU, R., VELUMURI, L., LINGAM, V., GEORGE, R., Ophthalmic Physiol Opt, 32, 2012, p. 39.

4. LANDERS, J., HENDERSON, T., CRAIG, J., Clin Exp Ophthalmol, 39, 2011, p. 604.

5. PYO, E., MUN, G., YOON, K., Epidemiol Health, 38, 2016, p. 6041. 6. SHERWIN, J., HEWITT, A., KEARNS, L., GRIFFITHS, L., MACKEY, D., CORONEO, M., Acta Ophthalmol, 91, 2013, p. 363.

7. LIU, L., WU, J., GENG, J., YUAN, Z., HUANG, D., BMJ Open, 3, 2013, p. 37.

8. MAHARJAN, I., SHRESHTH, E., GURUNG, B., KARMACHARYA, S., Nepal J Ophthalmol, 6, 2014, p. 65.

9. CHEN, T., DING, L., SHAN, G., KE, L., MA, J., ZHONG, Y., Invest Ophthalmol Vis Sci, 56, 2015, p. 1109.

10. TANO, T., ONO, K., HIRATSUKA, Y., OTANI, Y., SEKIGUCHI, M., KONNO, S., KIKUCHI, S., ONISHI, Y., TAKEGAMI, M., YAMADA, M., FUKUHARA, S., MURAKAMI, A., Acta Ophthalmol, 91, 2013, p. 232.

11. CORONEO, M., Br. J. Ophthalmol, 77, 1993, p. 734.

12. CAJUCOM-UY, H., TONG, L., WONG, T., TAY, W., SAW, S., Br J Ophthalmol, 94, 2010, p. 977.

13. SUN, N., ZHANG, H., Biosci Rep, 38, 2018.

14. FUEST, M., JODHBIR, S., CORONEO, M., Expert Review of Ophthalmology, 12, 2017, p. 193.

15. CHUI, J., CORONEO, M.T., TAT, L.T., CROUCH L., WAKEFIELD, D., DI GIROLAMO, N., Am J Pathol, 178, 2011, p. 817.

16. KAUFMAN, S., JACOBS, D., LEE, W., DENG, S., ROSENBLATT, M., SHTEIN, R., Ophthalmology, 120, 2013, p. 201.

17. RIM, T., KANG, M., CHOI, M., SEO K., KIM, S., PLOS One, 12, 2017, p. e0171954.

18. LIVEZEANU, C., CRAITOIU, M.M., MANESCU R., MOCANU, C.L., CRAITOIU, S., Rom J Morphol Embryol, 52, 2011, p. 837.

19. BENNETT HALL, A., Community Eye Health, 29, 2016, p. 54.

20. WANZELER, A.C.V., DUARTE, B., DUARTE MORON DE ANDRADE, V., ALVES, M., Clin Ophthalmol, 12, 2018, p. 833.

21. MERCUT (NICOLCESCU), M.F., CRAITOIU, S., MOCANU C.L., STEFANESCU-DIMA, A., BALASOIU, A., MERCUT, R., IONESCU, A.G., IONESCU, M., Rev. Chim(Bucharest), 70, no.5, 2019, p. 1843.

22. VARGHESE, M., GRIFFIN, C., MCKERNAN, K., ETER, L., LANZETTA, N., AGARWAL, D., ABRISHAMI, S., SINGER, K., Endocrinology, 160, 2019, p. 293.

23. HUNTER, L., J AYACHANDRAN, M., MILLER, V., Biol Sex Differ, 10, 2019, p. 26.

24. MAITAN SANTOS, B., NASCIMENTO, G., CAPEL, C., BORGES, G., ROSOLEN, T., SABINO, J., LEITE-PANISSI, C., BRANCO, L., Am J Physiol Regul Integr Comp Physiol, 2019.

25. SCOTLAND, R., STABLES, M., MADALLI, S., WATSON, P., GILROY, D., Blood, 118, 2011, p. 5918.

26. PECK, T., OLSAKOVSKY, L., AGGARWAL, S., J Midlife Health, 8, 2017, p. 51.

27. ONKAR, A., JI PANDEY, D., BIST, H.K., SEN, S., J Eye Cataract Surg, 3, 2017.

28. WANG, S., JIANG, B., GU. Y., Ophthalmic Res, 45, 2011, p. 210. 29. KAMPITAK, K., LEELAWONGTAWUN, W., LEEAMORNSIRI, S., SUPHACHEARA-PHAN, W., Acta Ophthalmol., 95, 2017, p. e227.

30. BARTLEY, E., FILLINGIM, R., Br J Anaesth, 111, 2013, p. 52.

31. NAZARE, M.S.L.D, SILVA, J.A.M.G., NAVEGA, M.T., FAGNELLONAVEGA, F.R., Fisioterapia em Movimento, 27, 2014, p. 77.

32. LOREN, J., ACLAND, E., CHO, C., Current Biology, 29, 2019.

33. WOLKOFF, P., Indoor Air., 27, 2017, p. 246.

34. ROHIT VERMA, R., BALHARA, Y.P.S., GUPTA, C.S., Ind Psychiatry J, 20, 2011, p. 4.

\section{Manuscript received: 3.04 .2019}

